Perbedaan Kemampuan Membaca....(Falina Noor Amalia)

\title{
PERBANDINGAN KEMAMPUAN MEMBACA CERITA RAKYAT SUMATERA SELATAN DAN CERITA PENDEK TEBITAN KOMPAS
}

\author{
Oleh: Falina Noor Amalia \\ (Dosen Universitas Tridinanti Palembang) \\ Email : falinanoor@univ-tridinanti.ac.id
}

\begin{abstract}
Abstrak
Penelitian ini bertujuan mengetahui perbandingan kecepatan membaca cerita rakyat Sumatera Selatan dan cerita pendek tebitan Kompas. Yang menjadi sampel dalam penelitian ini adalah Mahasiswa Semester II Program Studi Pendidikan Bahasa dan Sastra Indonesia, Fakultas Keguruan dan Ilmu Pendidikan Universitas Tridinanti Palembang. Teknik analisis data adalah teknik tes. Teknik penganalisis data kuantitatif digunakan untuk menganalisis hasil tes kecepatan membaca berupa nilai rerata. Teks yang digunakan adalah cerita rakyat Sumatera Selatan yang berjudul Sembesat dan Sembesit, sedangkan cerita pendek terbitan Kompas merupakan karangan Farizal Sikumbang yang berjudul Penagih Hutang Bersepeda Kumbang. Prosedur penganalisisan data adalah mengukur kecepatan membaca (KM), mengukur pemahaman isi (PI), dan mengukur kemampuan membaca (KMP). Teks yang diujikan adalah cerita rakyat Sumatera Selatan dan cerita pendek tebitan Kompas. Berdasarkan hasil penelitian, ditemukan bahwa kecepatan membaca cerita rakyat Sumatera Selatan adalah 161,71 kpm dengan tingkat pemahaman 34,04\%, sedangkan kecepatan membaca cerita pendek tebitan Kompas adalah 203,71 kpm dengan tingkat pemahaman 62,14\%. Hal ini menunjukkan bahwa tingkat kecepatan membaca mahasiswa dalam membaca cerita rakyat lebih rendah dibandingkan dengan cerita pendek terbitan
\end{abstract}

Kata Kunci : Kecepatan Membaca, Cerita Rakyat, Cerita Pendek.

\section{COMPARISON OF ABILITY TO READ PEOPLE'S STORIES SOUTH SUMATERA AND SHORT TEBITAN COMPASS STORIES}

\begin{abstract}
This research was aimed to find out the comparison of the speed of reading the folklore of South Sumatra and the short story published by Kompas. The sample in this study is the Second Semester Students of Indonesian Language and Literature Education Program, Faculty of Teacher Training and Education Tridinanti University of Palembang. The technique of data analysis was a test technique. Quantitative data analysis technique was used to analyze the mean of reading comprehension test result. The text used is South Sumatra folklore entitled Sembesat and Sembesit, while the short story published by Kompas is written by Farizal Sikumbang entitled Penagih Hutang Bersepeda Kumbang. The procedures of data analysis consisted of measuring the speed reading (KM), content comprehension (PI), and reading abilitzy (KMP). The texts being tested
\end{abstract}


are South Sumatran folklore and the short story published by Kompas. Based on the result of research, it was found that the reading speed of South Sumatera folklore was 161,71 kpm with the comprehension level 34,04\%, while the speed of reading narrative story published by Kompas is 203,71 kpm with understanding level $62,14 \%$. This shows that the reading speed of students in reading folklore is lower than the short story published by Kompas.

Keywords: Speed Reading, Folklore, Short Stories

\section{A. PENDAHULUAN}

Keterampilan membaca merupakan salah satu dari keempat keterampilan berbahasa: keterampilan menyimak, keterampilan berbicara, dan keterampilan menulis. Keterampilan membaca sangat diperlukan oleh seorang mahasiswa dalam proses belajar. Hal ini karena keterampilan ini berkaitan erat dengan keterampilan menulis. Menurut Amalia (2017:43), keterampilan membaca merupakan stimulus atau pancingan untuk keterampilan menulis.

Membaca adalah proses pengolahan bacaan secara kritis-kreatif yang dilakukan pembaca untuk memperoleh pemahaman menyeluruh tentang bacaan itu, yang diikuti oleh penilaian terhadap keadaan, nilai, fungsi, dan dampak bacaan itu (Nurhadi, 2016b:2). Berdasarkan pengertian tersebut, terlihat jelas bahwa kegiatan membaca tidak hanya terbatas pada memperoleh informasi saja. Kegiatan membaca juga melibatkan penilaian terhadap isi bacaan. Hal ini berarti diperlukan pemahaman terhadap teks yang telah dibaca untuk kemudian dilakukan penilaian. Pemahaman terhadap isi teks dapat dilihat dari terjawabnya pertanyaan-pertanyaan mengenai isi teks. Semakin banyak pertanyaan yang terjawab, semakin tinggi pula tingkat pemahamannya. Seseorang dapat dikatakan memiliki pemahaman yang baik terhadap teks apabila dapat menjawab pertanyaan mengenai teks antara 40-60\% (Nurhadi, 2016a:64).

Membaca pemahaman sering dikaitkan dengan kecepatan membaca. Kecepatan membaca mengandung berbagai implikasi seperti tujuan membaca, tingkat keterbacaan bahan bacaan, teknik membaca, motivasi, dan penalaran (Tampubolon, 2015:7). Membaca pemahaman dan kecepatan membaca tidak dapat dipisahkan karena memiliki hubungan satu sama lain. Kecepatan membaca saja tidak dapat menggambarkan kemampuan seseorang, begitu pula sebaliknya. 
Perbedaan Kemampuan Membaca....(Falina Noor Amalia)

Pemahaman bacaan lebih dari $60 \%$ pun belum dapat dikatakan baik apabila kecepatan membacanya masih lambat. Oleh karena itu, yang dapat menggambarkan keduanya adalah kemampuan membaca. Kemampuan membaca ialah kecepatan membaca dan pemahaman isi secara keseluruhan.

Setiap orang memiliki kecepatan membaca yang berbeda-beda. Seorang siswa SD maupun SMP sebaiknya memiliki kecepatan membaca $200 \mathrm{kpm}$, siswa SMA yaitu 250 kpm, dan mahasiswa yaitu 325 kpm (Nurhadi, 2016a:63-64). Kecepatan ini dapat disesuaikan dengan jenis teks yang dibaca karena kecepatan membaca juga bergantung pada jenis teks. Akan tetapi, walaupun kecepatan membaca disesuikan dengan jenis teks, kecepatan membaca pun memiliki beberapa kategori, yaitu:

1. kecepatan antara 500-800 kpm, kategori tinggi,

2. kecepatan antara $350-500 \mathrm{kpm}$, kategori cepat,

3. kecepatan antara $200-350 \mathrm{kpm}$, kategori rata-rata, dan

4. kecepatan antara 100-200 kpm, kategori lambat. (Mulyati, 2003)

Terdapat banyak jenis teks yang dapat digunakan untuk mengukur kemampuan membaca seseorang. Jenis teks yang paling sering digunakan adalah teks umum dan berita. Kedua jenis teks ini merupakan teks nonfiksi. Teks nonfiksi dipilih karena tujuan membacanya lebih terarah, yaitu mencari informasi pokok yang berupa apa, siapa, kapan, di mana, mengapa, dan bagaimana. Informasi pokok tersebut lazim disingkat menjadi $5 \mathrm{~W}+1 \mathrm{H}$ : What, Where, When, Why, Who, dan How.

Informasi pokok yang terdapat pada berita maupun teks umum tersebar dalam bacaan. Biasanya $5 \mathrm{~W}+1 \mathrm{H}$ ini tersurat dalam bacaan sehingga memudahkan pembaca mencari informasi pokok tersebut. Pembaca tidak perlu membaca keseluruhan kalimat yang terdapat di dalam bacaan. Pembaca cukup melakukan teknik skimming untuk menemukann informasi yang diperlukan. Teknik ini akhirnya membuat kecepatan membaca teks umum maupun berita menjadi lebih cepat, sehingga KPM-nya pun semakin tinggi.

Teks umum dan berita sangat berbeda dengan teks fiksi berupa cerita pendek. Cerita pendek merupakan teks fiksi, bukan teks nonfiksi seperti teks 
umum dan berita. Karena jenisnya berbeda, cara atau teknik membacanya pun berbeda. $5 \mathrm{~W}+1 \mathrm{H}$ tidak dapat diterapkan pada teks cerita pendek. Hal ini disebabkan oleh informasi yang diperlukan pembaca untuk memahami sebuah cerita pendek lebih banyak daripada teks umum dan berita.

Cerita pendek memiliki berbagai unsur yang terkandung di dalamnya. Kosasih (2012:34-41) menjelaskan bahwa unsur cerita terdiri dari alur, penokohan, latar, tema, dan amanat. Apabila pembaca telah dapat menjawab pertanyaan mengenai unsur-unsur tersebut, barulah pembaca dapat dikatakan telah memahami bacaan. Hal ini membuat kecepatan membaca cerita akan menjadi lebih lama dibandingkan membaca teks umum dan berita. Membaca cerita tidak dapat dilewatkan setiap bagiannya karena unsur-unsurnya cenderung tersirat pada setiap kalimat dalam bacaan.

Pengamatan awal dilakukan untuk mendapatkan data yang akurat mengenai kemampuan membaca mahasiswa. Peneliti menyebarkan tes yang terdiri atas tiga jenis tes bahan bacaan. Bahan tes tersebut terdiri dari jenis bahan bacaan umum, berita, dan sastra. Untuk menguji pemahaman terhadap bacaan, diberikan tes berupa 20 bentuk soal objektif. Pengambilan data dilaksanakan pada Mahasiswa Semester II Program Studi Pendidikan Bahasa dan Sastra Indonesia, Fakultas Keguruan dan Ilmu Pendidikan Universitas Tridinanti Palembang. Hasil rerata yang didapat dari pengamatan awal tersebut adalah $244 \mathrm{kpm}$ dengan tingkat pemahaman $61,11 \%$.

Penelitian ini dilakukan untuk melihat perbandingan kemampuan membaca cerita rakyat Sumatera Selatan dan cerita pendek tebitan Kompas yang diperoleh dari hasil bacaan Mahasiswa Semester II Program Studi Pendidikan Bahasa dan Sastra Indonesia, Fakultas Keguruan dan Ilmu Pendidikan Universitas Tridinanti Palembang.

Keterampilan membaca merupakan keterampilan berbahasa yang sangat penting dalam proses pembelajaran. Membaca dilakukan untuk memperoleh informasi yang terdapat dalam sebuah teks. Karena itulah Tarigan (2015:7) menyimpulkan membaca sebagai sebuah kegiatan proses penyandian kembali dan pembacaan sandi (decoding). 
Kecepatan membaca dan pemahaman bacaan merupakan satu kesatuan. Menurut Nurhadi (2016a:57), kecepatan membaca dan daya serap atau pemahaman adalah tolok ukur daya baca seseorang. Jadi walaupun seseorang membaca dengan kecepatan lebih dari $350 \mathrm{kpm}$, jika pemahamannya kurang dari $50-60 \%$ maka kemampuan membaca orang tersebut belum dapat dikatakan baik. Kecepatan membaca harus sejalan dengan pemahaman bacaan.

Terlepas dari pentingnya seseorang untuk menerapkannya, membaca cepat tidak dapat dilakukan oleh semua orang. Membaca cepat memiliki kesulitan yang tidak ditemukan pada kegiatan membaca biasa atau membaca dalam kecepatan lambat. Apabila seseorang yang tidak terbiasa membaca cepat mencoba untuk membaca dengan cepat, kemungkinan yang terjadi adalah dia justru tidak mendapatkan informasi yang terdapat dalam bacaan. Hal tersebut karena membaca cepat tidak dapat dipaksakan. Karena membaca merupakan suatu keterampilan, maka begitu juga dengan membaca cepat yang memerlukan latihan agar menjadi terampil.

Selain kecepatan membaca, membaca pemahaman juga harus ditingkatkan agar kemampuan membaca dapat meningkat. Kebanyakan pembaca lebih mementingkan salah satu hal saja. Padahal kecepatan dan pemahaman adalah dua hal yang tidak dapat dipisahkan. Apabila pembaca terlalu mementingkan kecepatan, ia mengabaikan pemahaman. Begitu pula sebaliknya.

Cerita pendek merupakan cerita yang menurut fisiknya berbentuk pendek (Kosasih, 2012:34). Jumlah kata dalam cerpen relatif singkat, hanya sekitar 500_ 5.000 kata. Cerita yang disajikan pada cerita pendek (cerpen) lebih sederhana dengan konlik yang singkat. Tema yang terdapat pada cerpen juga lebih mengarah ke kehidupan sehari-hari.

Selain cerpen, salah satu contoh karya sastra prosa fiksi lainnya adalah cerita rakyat. Cerita rakyat mirip seperti cerpen, perbedaannya hanya terletak pada masa atau tahun pembuatannya. Cerpen lebih modern dibandingkan cerita rakyat karena cerita rakyat cenderung berisikan cerita tentang asal usul suatu tempat atau peristiwa pada masa lampau. 
Cerita rakyat merupakan salah satu jenis karya sastra melayu klasik (Kosasih, 2012:21). Karya sastra jenis ini memiliki perbedaan dengan prosa lain seperti cerita pendek dan novel. Secara umum, unsur cerita rakyat statis dan kaku. Cerita rakyat dari Sumatera Selatan yang terkenal berjudul Sembesat \& Sembesit. Cerita ini berasal dari salah satu daerah di Sumatera Selatan, yaitu Besemah.

Teknik membaca cerita, cerita pendek maupun cerita rakyat, tentu saja berbeda dengan teknik membaca teks umum atau berita. Membaca cerita lebih sulit dibandingkan membaca berita dan teks umum. Untuk menemukan informasi penting dalam cerita tidak cukup hanya mencari $5 \mathrm{~W}+1 \mathrm{H}$ saja. Terdapat unsur lain yang juga perlu ditemukan dalam sebuah cerita agar dapat memahami bacaan.

\section{B. METODOLOGI PENELITIAN}

Penelitian kemampuan membaca Mahasiswa Semester II Program Studi Pendidikan Bahasa dan Sastra Indonesia Fakultas Keguruan dan Ilmu Pendidikan Universitas Tridinanti Palembang menggunakan pendekatan kuantitatif. Hasil data dari penyebaraan tes pemahaman dianalisis secara statistik deskriptif. Metode ini digunakan untuk meneliti populasi atau sampel tertentu serta pengumpulan data menggunakan instrumen penelitian (Sugiyono, 2012:8)

Populasi yang digunakan dalam penelitian ini adalah seluruh Mahasiswa Semester I Program Studi Pendidikan Bahasa dan Sastra Indonesia yang berjumlah 21 orang.

Dalam pengumpulan data, instrumen penelitian yang digunakan dalam penelitian tindakan kelas ini adalah instrumen tes dan instrumen nontes. Dalam hal ini, peneliti menyebarkan tes yang berupa dua teks cerita yang berbeda, yaitu cerita pendek dari Harian Kompas karangan Farizal Sikumbang yang berjudul Penagih Hutang Bersepeda Kumbang dan cerita rakyat dari Besemah, Sumatera Selatan. Untuk menguji pemahaman akan isi teks, diberikan tes objektif berupa 20 soal pemahaman. Hasil tersebut akan mencerminkan tingkat pemahamannya terhadap teks yang telah dibaca (Amalia, 2017:47). 
Perbedaan Kemampuan Membaca....(Falina Noor Amalia)

Tabel 1 Kategori Penilaian Pemahaman Membaca Cepat

\begin{tabular}{|c|c|c|}
\hline No. & Rentang Nilai & Kategori \\
\hline 1 & $91-100$ & Sangat baik \\
\hline 2 & $61-90$ & Baik \\
\hline 3 & $41-60$ & Cukup \\
\hline 4 & $21-40$ & Kurang \\
\hline 5 & $0-20$ & Sangat kurang \\
\hline
\end{tabular}

(Nurhadi, 2016a:64)

Prosedur penelitian diawali dengan mahasiswa mempersiapkan diri untuk mengukur kecepatan membaca menggunakan stopwatch sebagai alat pengukur. Setelah teks bacaan dibagikan, mahasiswa dipersilakan untuk mulai membaca. Stopwatch dihentikan ketika pembacaan selesai. Waktu yang diperoleh untuk membaca satu teks tersebut dicatat untuk kemudian dihitung menggunakan rumus kecepatan membaca. Untuk mengukur pemahaman, mahasiswa dipersilakan untuk menjawab soal-soal pemahaman yang telah disediakan. Ketika menjawab soal, mahasiswa tidak diperbolehkan melihat kembali isi teks karena untuk menguji pemahaman, hanya mengandalkan ingatan ketika membaca teks sebelumnya.

Teknik analisis data untuk mengukur pemahaman digunakan rerata yang diperoleh dari hasil tes. Nilai rerata membaca pemahaman dianalisis dengan statistik deskriptif. Berikut rumus yang digunakan untuk mengukur kemampuan membaca berdasarkan Tampubolon (2008:11-12).

a. Kecepatan Membaca

$$
K M=\frac{\text { Jumlah Kata }}{\text { WaktuBaca(menit) }}
$$

b. Pemahaman Isi

$$
P I=\frac{\text { Jawaban Benar }}{\text { Jumlah Soal }} \times 100 \%
$$

Hasil yang diperoleh dari kedua teks kemudian dibandingkan, manakah di antara kedua teks tersebut yang lebih dikuasai mahasiswa, dilihat dari kecepatan membaca dan membaca pemahaman.

\section{HASIL DAN PEMBAHASAN}

\section{Rerata Skor Kecepatan Membaca Cerita Rakyat}

Hasil skor rerata kecepatan membaca cerita rakyat oleh Mahasiswa Semester II Program Studi Pendidikan Bahasa dan Sastra Indonesia Fakultas Keguruan dan 
Ilmu Pendidikan Universitas Tridinanti Palembang yang berjumlah 21 orang mahasiswa dengan kategori yang berbeda-beda, sebagaimana yang terdapat pada tabel berikut.

Tabel 2 Rerata Skor Kecepatan Membaca Cerita Rakyat

\begin{tabular}{|c|c|c|}
\hline No. & Inisial Mahasiswa & Nilai Rerata \\
\hline 1 & IK & 134 \\
\hline 2 & TY & 118 \\
\hline 3 & AI & 88 \\
\hline 4 & DS & 129 \\
\hline 5 & AL & 153 \\
\hline 6 & SR & 159 \\
\hline 7 & NN & 159 \\
\hline 8 & VV & 76 \\
\hline 9 & LI & 151 \\
\hline 10 & MF & 90 \\
\hline 11 & SM & 293 \\
\hline 12 & TR & 229 \\
\hline 13 & MR & 112 \\
\hline 14 & NC & 254 \\
\hline 15 & NV & 150 \\
\hline 16 & RU & 389 \\
\hline 17 & YD & 159 \\
\hline 18 & WN & 93 \\
\hline 19 & WL & 142 \\
\hline 20 & DA & 176 \\
\hline 21 & VI & 142 \\
\hline & JUMLAH & $\mathbf{3 . 3 9 6}$ \\
\hline & RERATA & $\mathbf{1 6 1 , 7 1 ~ k p m ~}$ \\
\hline
\end{tabular}

Berdasarkan tabel rerata skor kecepatan membaca cerita rakyat, ditemukan bahwa rerata kecepatan membaca mahasiswa mencapai 161,71 kpm. Nilai tersebut masuk dalam kriteria lambat karena belum mencapai $200 \mathrm{kpm}$.

\section{Rerata Skor Pemahaman Membaca Cerita Rakyat}

Hasil skor rerata pemahaman bacaan cerita rakyat oleh Mahasiswa Semester II Program Studi Pendidikan Bahasa dan Sastra Indonesia Fakultas Keguruan dan Ilmu Pendidikan Universitas Tridinanti Palembang yang berjumlah 21 orang mahasiswa dengan kategori yang berbeda-beda, sebagaimana yang terdapat pada tabel berikut. 
Perbedaan Kemampuan Membaca....(Falina Noor Amalia)

Tabel 3 Rerata Skor Pemahaman Membaca Cerita Rakyat

\begin{tabular}{|c|c|c|}
\hline No. & Inisial Mahasiswa & Nilai Rerata \\
\hline 1 & IK & 10 \\
\hline 2 & TY & 15 \\
\hline 3 & AI & 30 \\
\hline 4 & DS & 20 \\
\hline 5 & AL & 30 \\
\hline 6 & SR & 15 \\
\hline 7 & NN & 10 \\
\hline 8 & VV & 10 \\
\hline 9 & LI & 15 \\
\hline 10 & MF & 60 \\
\hline 11 & SM & 20 \\
\hline 12 & TR & 50 \\
\hline 13 & MR & 50 \\
\hline 14 & NC & 50 \\
\hline 15 & NV & 60 \\
\hline 16 & RU & 50 \\
\hline 17 & YD & 50 \\
\hline 18 & WN & 40 \\
\hline 19 & WL & 45 \\
\hline 20 & DA & 45 \\
\hline 21 & VI & 40 \\
\hline & JUMLAH & $\mathbf{7 1 5}$ \\
\hline & RERATA & $\mathbf{3 4 , 0 4} \%$ \\
\hline
\end{tabular}

Berdasarkan tabel rerata skor pemahaman membaca cerita rakyat, ditemukan bahwa rerata membaca pemahaman mencapai 34,04\%. Nilai tersebut belum masuk dalam kriteria baik karena belum mencapai $60 \%$.

\section{Rerata Skor Kecepatan Membaca Cerita Pendek}

Hasil skor rerata kecepatan membaca cerita pendek oleh Mahasiswa Semester II Program Studi Pendidikan Bahasa dan Sastra Indonesia Fakultas Keguruan dan Ilmu Pendidikan Universitas Tridinanti Palembang yang berjumlah 21 orang mahasiswa dengan kategori yang berbeda-beda, sebagaimana yang terdapat pada tabel berikut.

Tabel 4 Rerata Skor Kecepatan Membaca Cerita Pendek

\begin{tabular}{|c|c|c|}
\hline No. & Inisial Mahasiswa & Nilai Rerata \\
\hline 1 & IK & 247 \\
\hline 2 & TY & 174 \\
\hline
\end{tabular}




\begin{tabular}{|c|c|c|}
\hline No. & Inisial Mahasiswa & Nilai Rerata \\
\hline 3 & AI & 171 \\
\hline 4 & DS & 164 \\
\hline 5 & AL & 181 \\
\hline 6 & SR & 295 \\
\hline 7 & NN & 157 \\
\hline 8 & VV & 145 \\
\hline 9 & LI & 154 \\
\hline 10 & MF & 146 \\
\hline 11 & SM & 406 \\
\hline 12 & TR & 257 \\
\hline 13 & MR & 164 \\
\hline 14 & NC & 205 \\
\hline 15 & NV & 131 \\
\hline 16 & RU & 288 \\
\hline 17 & YD & 155 \\
\hline 18 & WN & 164 \\
\hline 19 & WL & 199 \\
\hline 20 & DA & 262 \\
\hline 21 & VI & 213 \\
\hline & JUMLAH & $\mathbf{4 . 2 7 8}$ \\
\hline & RERATA & $\mathbf{2 0 3 , 7 1 ~ k p m ~}$ \\
\hline
\end{tabular}

Berdasarkan tabel rerata skor kecepatan membaca cerita pendek, ditemukan bahwa rerata kecepatan membaca mahasiswa mencapai 203,71 kpm. Nilai tersebut masuk dalam kriteria rata-rata karena telah mencapai 200 kpm.

\section{Rerata Skor Pemahaman Membaca Cerita Pendek}

Hasil skor rerata pemahaman bacaan cerita pendek oleh Mahasiswa Semester II Program Studi Pendidikan Bahasa dan Sastra Indonesia Fakultas Keguruan dan Ilmu Pendidikan Universitas Tridinanti Palembang yang berjumlah 21 orang mahasiswa dengan kategori yang berbeda-beda, sebagaimana yang terdapat pada tabel berikut.

Tabel 5 Rerata Skor Pemahaman Membaca Cerita Pendek

\begin{tabular}{|c|c|c|}
\hline No. & Inisial Mahasiswa & Nilai Rerata \\
\hline 1 & IK & 60 \\
\hline 2 & TY & 30 \\
\hline 3 & AI & 60 \\
\hline 4 & DS & 65 \\
\hline 5 & AL & 55 \\
\hline 6 & SR & 35 \\
\hline
\end{tabular}




\begin{tabular}{|c|c|c|}
\hline No. & Inisial Mahasiswa & Nilai Rerata \\
\hline 7 & $\mathrm{NN}$ & 70 \\
\hline 8 & VV & 55 \\
\hline 9 & LI & 55 \\
\hline 10 & $\mathrm{MF}$ & 90 \\
\hline 11 & SM & 65 \\
\hline 12 & TR & 65 \\
\hline 13 & MR & 70 \\
\hline 14 & $\mathrm{NC}$ & 70 \\
\hline 15 & NV & 70 \\
\hline 16 & RU & 60 \\
\hline 17 & YD & 70 \\
\hline 18 & WN & 45 \\
\hline 19 & WL & 75 \\
\hline 20 & DA & 75 \\
\hline 21 & VI & 65 \\
\hline \multicolumn{2}{|r|}{ JUMLAH } & 1.305 \\
\hline \multicolumn{2}{|r|}{ RERATA } & $62,14 \%$ \\
\hline
\end{tabular}

Berdasarkan tabel rerata skor pemahaman membaca cerita rakyat, ditemukan bahwa rerata membaca pemahaman mencapai 62,14\%. Nilai tersebut masuk dalam kriteria baik karena lebih dari $60 \%$ mahasiswa memiliki pemahaman isi bacaan.

\section{Kemampuan Membaca Cerita Rakyat dan Cerita Pendek}

Berdasarkan penelitian yang telah dilakukan, ditemukan ringkasan data sebagai berikut.

Tabel 6 Kemampuan Membaca

\begin{tabular}{|l|c|c|}
\hline & Cerita Rakyat & Cerita Pendek Kompas \\
\hline Kecepatan Membaca & $161,71 \mathrm{kpm}$ & $203,71 \mathrm{kpm}$ \\
\hline Pemahaman Bacaan & $34,04 \%$ & $62,14 \%$ \\
\hline
\end{tabular}

Terdapat perbedaan signifikan antara kecepatan membaca cerita rakyat dan cerita pendek, yaitu sebesar $42 \mathrm{kpm}$ antara cerita rakyat sebesar 161,71 kpm dan cerita pendek Kompas sebesar 203,71 kpm. Perbedaan ini dirasakan cukup jauh dan signifikan. Hal ini karena kecepatan membaca untuk cerita rakyat masuk dalam kategori lambat, sedangkan kecepatan membaca cerita pendek masuk dalam kategori rata-rata. Walaupun kecepatan membaca kategori rata-rata belum 
sesuai dengan tingkatan mahasiswa, kecepatan membaca ini lebih baik dibandingkan dengan kecepatan membaca cerita rakyat.

Hasil kecepatan membaca yang rendah ini disebabkan oleh banyak faktor. Menurut Noer (2010:41), faktor yang menghambat seseorang dalan membaca cepat diantaranya adalah sulit konsentrasi; rendahnya motivasi; khawatir tidak memahami bahan bacaan; kebiasaan-kebiasaan buruk dalam membaca. Dalam hal ini, faktor yang paling mungkin muncul adalah kurang memahami bacaan. Cerita rakyat yang berlatarkan masa lampau dan penggunaan bahasa yang lawas juga dapat menjadi faktor penghambat mahasiswa untuk memahami isi bawaan dengan baik. Hal ini juga dibuktikan dengan rendahnya tingkat pemahaman, yaitu sebesar $34,04 \%$ untuk membaca cerita rakyat. Berbeda jauh dengan cerita pendek Kompas yang cenderung menggunakan bahasa yang mudah dipahami, sehingga tingkat pemahaman bacaannya pun mencapai $62,14 \%$ yang berarti telah memasuki kategori baik.

\section{SIMPULAN}

Kecepatan membaca seseorang memiliki tingkatan yang berbeda-beda. Kecepatan membaca dapat disesuaikan dengan teks yang dibaca. Ketika membaca teks umum atau berita, pembaca cenderung membaca lebih cepat dibandingkan dengan ketika membaca teks sastra berupa prosa fiksi. Hal ini karena prosa, misalnya cerita, memiliki berbagai unsur yang harus ditemukan oleh pembaca ketika kegiatan membaca berlangsung. Sedangkan teks umum dan berita dapat dibaca relatif lebih cepat karena informasi yang harus ditemukan berupa $5 \mathrm{~W}+1 \mathrm{H}$ saja.

Terdapat berbagai jenis prosa fiksi, diantaranya adalah cerita rakyat dan cerita pendek. Cerita pendek (cerpen) lebih modern dibandingkan cerita rakyat karena cerita rakyat cenderung berisikan cerita tentang asal usul suatu tempat atau peristiwa pada masa lampau. Perbedaan isi ini juga menyebabkan perbedaan kemampuan membaca kedua teks tersebut.

Berdasarkan penelitian yang dilakukan, ditemukan bahwa kecepatan membaca cerita rakyat adalah $161,71 \mathrm{kpm}$ dengan pemahaman $34 \%$. Hasil ini 
termasuk dalam kategori membaca lambat dengan pemahaman tidak baik. Berbeda dengan kecepatan membaca cerita pendek Kompas yang masuk dalam kategori rata-rata yaitu 203,71 kpm dengan pemahaman baik yaitu sebesar $62,14 \%$.

Dari paparan hasil penelitian tersebut, kemampuan membaca cerita rakyat lebih rendah dibandingkan cerita pendek Kompas. Banyak faktor yang memengaruhinya, salah satunya adalah kurangnya pemahaman dan minat mahasiswa terhadap teks sastra lama. Hal ini menyebabkan kegiatan membaca terhambat karena mahasiswa kurang memahami isi bacaan

\section{DAFTAR PUSTAKA}

Amalia, Falina Noor. (2017). "Kemampuan Membaca Pemahaman Mahasiswa" Makalah. Disajikan pada Seminar Nasional Pendidikan Bahasa dan Sastra Indonesia, tanggal 25 November 2017 di Universitas Sriwijaya Palembang.

Kosasih, E. (2012). Dasar-dasar Keterampilan Berbahasa. Bandung: Yrama Widya.

Mulyati. (2003). "Kecepatan Efektif Membaca: Apa dan Bagaimana?" Makalah. Disajikan pada Diklat Membaca, Menulis, dan Apresiasi Sastra bagi Guru SLTP Se-Indonesia, tanggal 1-14 Oktober 2003 di Pusat Pengembangan Penataran Guru Bahasa Jakarta.

Nurhadi. (2016a). Strategi Meningkatkan Daya Baca. Jakarta: Bumi Aksara.

Nurhadi. (2016b). Teknik Membaca. Jakarta: Bumi Aksara.

Subadiyono, dkk. (2000). Sembesat Sembesit Kumpulan Cerita Rakyat Sumatera Selatan. Palembang: Balai Bahasa Palembang.

Tampubolon, D. P. (2015). Kemampuan Membaca, Teknik Membaca Efektif dan Efisien. Bandung: Angkasa.

Tarigan, Henry Guntur. (2015). Membaca Sebagai Suatu Keterampilan Berbahasa. Bandung: Angkasa. 